\title{
Inequality in school enrolment in Uganda among children of ages 6-17 years: the experience after introduction of universal primary education- UPE
}

\author{
Rutaremwa, Gideon; Bemanzi, Juliana \\ Center for Population and Applied Statistics - Makerere University, P.O.Box 7062, Kampala Uganda
}

Email address:

gideonrutaremwa@gmail.com (Rutaremwa, Gideon),julie.bemanzi@gmail.com (Bemanzi, Juliana)

\section{To cite this article:}

Rutaremwa, Gideon; Bemanzi, Juliana.Inequality in School Enrolment in Uganda among Children of Ages 6-17 Years: The Experience after Introduction of Universal Primary Education - UPE.Science Journal of Education. Vol. 1, No. 4, 2013, pp. 43-50.

doi: $10.11648 /$ j.sjedu.20130104.11

\begin{abstract}
In 1997 the government of Uganda introduced the policy of Universal Primary Education - UPE whose aim was to improve on school enrolment. Equal opportunity and access to education is a central theme in the political agenda of government of Uganda, indeed universal access to primary education is MDG Goal II, which governments world over are striving to achieve. Research has not established whether inequalities in access to education still exist a decade after UPE was introduced in the country. Using data from the Uganda National Household Survey 2009/2010, this paper attempts to examine this issue. A total of 12,424 children of ages 6-17 years are selected for study. A measure of unevenness - Theil's index and a multinomial logistic regression are fitted to the data, adjusted for a number of social and demographic characteristics. The findings suggest that $81 \%$ of the children were currently attending school. Gender inequalities in school enrolment were not supported by the regression model findings. However, substantial and significant differences were observed for the various regions of the country, rural-urban residence, poverty status age of child, and household size. Although not all factors affecting current enrolment among children were analyzed, the discourse in this paper suggests need for intervention to address specific child enrolment inequalities identified.
\end{abstract}

Keywords: Inequality, School Enrolment, Uganda, Children, Universal Primary Education

\section{Introduction}

Equal education opportunity is a widely agreed principle, almost universally considered to be a funding principle of education policy. Equal education opportunity principle is not controversial because it merges two powerful ideas: that all young individuals should have equal chance to succeed in life and that more hard working students should emerge in the education competition[1]. The International Covenant on Economic, Social and Cultural Rights (ICESCR) that was adopted in 1966 and came into force in 1976 addresses amongst other issues the right of the child to education. It is important to note here that Uganda ratified the ICESCR in 1987[2]. Another instrument that highlights the issue of universal and equitable access to education is the 1995 Copenhagen World Summit for Social Development (UN 1995). Notwithstanding, there is general agreement that education is critical to individuals, communities and society broadly [3].

\section{Theory and Relevant Literature}

Education has been identified as a key factor in economic and social development, and the equitable access to education of good quality has become a crucial objective of development policy. Countries with high levels of educational inequality consistently show lower levels of innovation, lower levels of production efficiency, and a tendency to transmit poverty across generations [4].Although there is a moral argument for reducing educational inequality, there is an economic argument as well: increased access to education by all helps middle- and lower-income groups realize the full potential of their talent, increasing the level of productivity, innovation, and investment in society and, by inference, increasing the level of welfare of its population [5, 6]. Education inequality can lead to socially undesirable and economically inefficient inter-generational persistence of inequality $[7,8,9,10]$. If there can be economic growth in the presence of 
educational inequality, there is compelling evidence showing a close connection between education and productivity and between productivity and income growth[11, 12, 13].

Research concerning gender in sub-Saharan Africa has consistently found females to be at a disadvantage $[3,14$, $15,16]$. The causes of this effect are explained variously by entrenched gender roles, cultural norms, religion, and the domestic workload of women. Although there is a pattern of decreased educational benefits for women, research concerning the effects of socioeconomic status by gender is somewhat more complicated. Evidence from Uganda suggests that the UPE programme has had a strong propoor and gender equalizing effect [17]. The enrolment of girls increased more than 300 percent between 1992/03 and 2002/03[18]. At the regional level, the impact was also significant. In the Northern region of Uganda, the increase in girls' enrolment between 1992/93 and 2002/03 was considerable, increasing from 39.7 percent to 72.5 percent respectively.

There has been limited research on sex of child and enrolment in Uganda. One study which exists on Uganda found that many students were not at the appropriate gradelevel, but did not establish a gender gap in age-appropriate enrolment[19, 20]. However, this was an economic development study that was not primarily interested in age differentials in enrolment. In addition, that study only reported descriptive statistics, and therefore could not investigate the nature of the relationship between age and enrolment.

Concerning the relationship between place of residence and school enrolment, the expectation is that children living in urban areas will exhibit higher enrolment rates compared to those in rural areas. However, studies from developed countries suggest the contrary [21]. Students from the inner city exhibited lower achievement and a higher likelihood of dropping out of school than do their suburban counterparts. Educational research and policy has tended to neglect these inequalities or, at best, focus on one type but not the other. In this study an attempt was made to examine how place of residence influences school enrolment in Uganda.

The poverty decline in Uganda has not been experienced uniformly across the country. In the Northern region of Uganda, for example, poverty decline has been modest at only approximately 17 percent since 1992/93. This is compared to substantial progress made in the West and Central regions of Uganda, where poverty has declined by around 60 percent since 1992/3 [22]. The slow progress in the North can be attributed to a vicious cycle of conflict, massive displacement, thwarted economic activity, complications in service delivery and the immense poverty that has gripped the northern region of the country [22]. Acquisition of education is a significant and indivisible investment; poverty often constitutes an impediment to acquiring education [23]. Poverty can hinder learning, as some children, particularly orphans and heads of households are forced to work before and after school. Food is often limited, making it difficult for children to concentrate. Conflict and resulting economic poverty also appear to be instrumental in perpetuating gender inequalities in relation to educational access. Rutaremwa [24] also shows that children who hailed from poor households in Uganda were more likely to be severely education deprived compared to their counterparts from the non-poor households.

Although some research in Africa supports the resourcedilution theory by concluding that larger households are associated with lower enrolments $[25,26]$. Other studies have concluded argued that larger families have positive educational effects [27, 28, 29]. Much of the research, however, implies more complex relationships. In one study the number of siblings was associated with higher dropout rates, but the author pointed out that the "associations are not necessarily causal, because parents who value education tend to have fewer children" [30].

In Uganda, a number of strategies have been put together to promote the right of children to education. Notably, the 1995 constitution of the Republic of Uganda established education as a right for all[2]. In addition in its report of 2004, the Uganda Human Rights Commission (UHRC) made it clear that the state had an obligation to establish sufficient schools and hire the required teachers and provide quality education put down in international rights instruments[31]. The government through the Universal Primary Education (UPE) has increased its spending to try and meet the demands of primary education. What is not clear, however, is whether these developments have resulted in marked achievements in the substance of the right to education and whether these rights to education and achievements can be sustainable. This paper seeks to address only some aspects of the former question: has equity in access to education been achieved a decade after the UPE programme was put in place. It is important to note, however that equitable access to schooling alone may not be a remedy for social transformation and development. The latter must be complemented with increases in the quality of education and changes in school governance to address the sustainability of reforms through increased accountability[32].

A number of strategies and programs have been put in place by the Uganda government to address issues of inequality in access to education. From a historical perspective, school education has continued to expand since 1962 when Uganda gained its independence. For example, in the year 2000, Uganda had 12,480 primary schools, but by 2012 , these numbers had grown to 22,510 primary schools [33].School education was introduced in Uganda by the White missionaries mainly for the children of chiefs and to provide for functionaries needed by the British colonial government[34], [35]. So right from the onset, this school system was not for all and it therefore grew to become highly selective and competitive with fewer and fewer students continuing to the next level of 
education. As a result, many Ugandans remained illiterate with literacy rates standing at only $65 \%$ with the primary education 'reaching only50 percent of the age group' [36]. It is against this background that in 1997 the UPE policy was launched by government in accordance with the government White Paper on Education [37]. Under this policy, the Uganda government aimed at providing 'free' education to a maximum of four children from each family. Among the major objectives of UPE was: 1). Making basic education accessible to the learners and relevant to their needs as well as meeting national goals; 2). Making education equitable in order to eliminate disparities and inequalities; 3).Establishing, providing and maintaining quality education as the basis for promoting the necessary human resource development; 4).Initiating a fundamental positive transformation of society in the social, economic and political field; 5). Ensuring that education is affordable by the majority of Ugandans by providing, initially the minimum necessary facilities and resources, and progressively the optimal facilities; and 6). Enable every child to enter and remain in school until they complete the primary education cycle [36].

Enrolment figures after the launching of UPE shot up from nearly 2.5 million in 1996 to nearly 6.6 million in 2000 and to 8.3 million in 2012[33]. This increase was mainly for two reasons, first, the backlog of school age children who had not been accessing school were now able to do so while more of the children who had attained the school age but would not have afforded education prior to UPE were now able to join school. This massive increase in pupil numbers immediately created a problem of classroom space. Although the Ministry soon embarked on a drive to build more schools, and provide instructional materials, this is still inadequate, as the Ministry acknowledges that: the increase in the number of schools has not kept pace with the increase in the number of students[23].Secondly, such developments have an important bearing on the quality of education offered in the Ugandan schools. There are fears that the massive numbers in schools without commensurate expansion in facilities, teachers, and teaching/learning materials have compromised the quality of education. Although no thorough studies have been carried out, the Ministry of Education and Sports voices this concern when in its report says, the quality of teaching could probably have been affected by the adverse pupil-teacher ratio after the introduction of UPE [35]. Notwithstanding, the current study only seeks to examine whether inequalities in access to education still exist and to highlight any such gaps.

\section{Data and Methods}

In this analysis, we use data from the Uganda National Household Survey (UNHS), which allows us track the individual child record within a household. The Uganda National Household Survey (UNHS) 2009/10 is part of a series of household surveys that started in 1989. The survey collected information on socioeconomic characteristics at household and community levels as well as information on the informal sector. The main objective of the survey was to collect data on population and socio-economic characteristics of households for monitoring development performance.A total of 12,424 young people of ages 6-17 years, comprising of $51 \%$ male and $49 \%$ female, were selected for investigation. The outcome variable had three categories; whether a child was enrolled in school at the time of the survey and whether the child had enrolled previously and whether the child had never enrolled in school. Descriptive analysis was done to compare the characteristics of children across the different socioeconomic and demographic backgrounds including residence, poverty status, region, age group and sex. In addition entropy scores and the corresponding entropy index were estimated in order to establish the level of evenness in school enrolment the various study population groups. Finally, a multinomial logistic regression with child enrolment status as the dependent variable was estimated.

The entropy index also known as the Theil index or "diversity index" measures the differences in the distributions of groups within a geographical area. The index allows for the calculation of measures for multiple groups simultaneously. Calculating the Theil index involves a multistep process in which an entropy score, a measure of diversity, is first calculated. The total area (country) entropy score is calculated from:

$$
E=\sum_{J=1}^{z}\left(X_{j}\right) \ln \left[\frac{1}{X_{j}}\right]
$$

Where $X_{j}$ is the share for the population of the entire area in each category of the variable studied and $\mathrm{Z}$ is the number of categories. The resulting number is the diversity of the total area, and the higher the number, the more diverse the area. The upper limit of the measure is given by the natural $\log$ of the number of groups used in the calculations. The upper limit is reached when all groups have equal representation within the area.

The next step is to measure the individual subunits' entropy score from:

$$
E_{i}=\sum_{J=1}^{z}\left(X_{J}\right) \ln \left[\frac{1}{X_{J}}\right]
$$

Where $\mathrm{X}_{\mathrm{J}}$ is the share of the total in each category of the variable studied for in the area subunit ${ }_{i}$.

Using the numbers generated from the preceding formulas, the Theil or entropy index can be calculated. This measure is interpreted as the weighted average deviation of each subunit's entropy from the total area's entropy. The final step is calculated from:

$$
H=\sum_{i=1}^{N}\left[t_{i}\left(E-E_{i}\right)\right] / E T
$$

Where $t_{i}$ represents total population of subunit $\mathrm{I}$ and $\mathrm{T}$ represents the total area population. The measure $(\mathrm{H}-$ 
entropy index) varies between 0.0 if all subunits have the same composition as the overall area to 1.0 if all subunits contain only one group.

Lastly, are gression model was fitted to the data in order to explore the association between a set of independent variables explaining the likelihood of one being in the currently enrolled category as opposed to being in all other categories. The form of the equation fitted to the data was as follows:

$$
\ln \frac{P\left(Y_{i}=m\right)}{P\left(Y_{i}=1\right)}=\alpha+\sum_{k=1}^{K} \beta_{x m} X_{i k}=Z_{m i}
$$

For a dependent variable that has 3 categories, this is represented by $m$ in the equation above, and this requires the calculations for $m-1$ equations, one for each category relative to the reference category to describe the relationship between child enrolment status and the independent variables. For group 2 of the dependent variable (currently enrolled), for example the following equation derived from the latter is then estimated:

$$
P\left(Y_{i}=m\right)=\frac{\exp \left(Z_{m i}\right)}{1+\sum_{h=2}^{M} \exp \left(Z_{h i}\right)}
$$

In the multinomial logistic regression, one category of the dependent variable (never enrolled) was chosen as the comparison category. Separate risk ratios are determined for all independent variables for each category of the dependent variable except the comparison category, which is omitted from the analysis. The model parameter estimates and the attendant relative risk ratios for the multinomial logit model is that for a unit change in the predictor variable, the logit of outcome $m$ relative to the reference group is expected to change by its respective parameter estimate given the variables in the model are held constant.

\section{Results and Discussion}

Table 1, Table 2 and Figure 1 present the descriptive statistics of the study population. In Table 1 the findings show that there are significant regional differences in the enrolment status of children of ages 6-17 years. Eastern region had the highest proportion of its children currently enrolled in schools $(87.7 \%)$, while northern region had the least $(74.3 \%)$. The findings also show that northern region had the largest proportion of children who had never attended school $(20.5 \%)$ followed by Western region with 12.8 percent. Furthermore, it was Central region that had the highest proportion of its children that were previously enrolled (6.6\%). Looking at rural-urban residence shows that the percentage who had never enrolled in school was twice as much in rural areas compared to urban areas, at the same time the percentage of children currently enrolled was higher in urban areas $(85.8 \%)$ compared to the rural areas $(80.7 \%)$. The urban areas also had a higher percentage of children previously enrolled in school compared to the rural areas.

With respect to poverty status, the findings in Table 1 show that over one fifth $(21.7 \%)$ of the poor children were never enrolled in school. Thus, despite the introduction of UPE a significant proportion of children as indicated are still deprived of education. With regard to household size, the results in Table 1 shows a clear increase in the proportion currently enrolled with increase of household size. The percentage of current enrolled children increased from 77.4 percent in households with 1-3 persons to 86.0 percent in households with 10 and more persons. The percentage previously enrolled-mainly those who had dropped out of school was highest in households of a small size (1-3 persons), at 12.0 percent.

Table 1: Descriptive statistics for selected indicator variables in the

\begin{tabular}{|c|c|c|c|c|}
\hline $\begin{array}{l}\text { Variable/ } \\
\text { category }\end{array}$ & $\begin{array}{l}\% \\
\text { Never } \\
\text { enrolled }\end{array}$ & $\begin{array}{l}\text { \% } \\
\text { Previously } \\
\text { enrolled }\end{array}$ & $\begin{array}{l}\text { \% } \\
\text { Currently } \\
\text { enrolled }\end{array}$ & Significance \\
\hline \multicolumn{5}{|l|}{ Region } \\
\hline Central & 9.5 & 6.6 & 83.9 & \\
\hline Eastern & 7.9 & 4.4 & 87.7 & $x^{2}=306.9$ \\
\hline Northern & 20.5 & 5.2 & 74.3 & $\mathrm{p}=0.000$ \\
\hline Western & 12.8 & 5.2 & 82.0 & \\
\hline \multicolumn{5}{|l|}{ Residence } \\
\hline Rural & 14.2 & 5.1 & 80.7 & $x^{2}=60.6$ \\
\hline Urban & 7.2 & 7.0 & 85.8 & $\mathrm{p}=0.000$ \\
\hline \multicolumn{5}{|c|}{ Poverty Indicator } \\
\hline Non-poor & 9.5 & 5.3 & 85.2 & $x^{2}=351.9$ \\
\hline Poor & 21.7 & 5.3 & 73.0 & $\mathrm{p}=0.000$ \\
\hline \multicolumn{5}{|l|}{ Household size } \\
\hline $1-3$ & 10.6 & 12.0 & 77.4 & \\
\hline 4-6 & 14.5 & 5.4 & 80.1 & $x^{2}=115.6$ \\
\hline 7-9 & 14.3 & 4.6 & 81.1 & $\mathrm{p}=0.000$ \\
\hline $10+$ & 9.8 & 4.2 & 86.0 & \\
\hline \multicolumn{5}{|l|}{ Sex of child } \\
\hline Male & 13.2 & 5.3 & 81.5 & $x^{2}=0.388$ \\
\hline Female & 13.6 & 5.3 & 81.1 & $\mathrm{p}=0.823$ \\
\hline \multicolumn{5}{|l|}{ Age Group } \\
\hline 6-9 years & 25.8 & 0.7 & 73.5 & \\
\hline 10-13years & 6.1 & 2.1 & 91.8 & $x^{2}=2000.0$ \\
\hline $14-17$ years & 5.2 & 15.8 & 79.0 & $\mathrm{p}=0.000$ \\
\hline Total (n) & 1,666 & 658 & 10,100 & \\
\hline
\end{tabular}
regression model $(N=12424)$

The relationship between enrolment status and sex of child was also examined and unfortunately there was no significant difference shown between male and female children. The effect of sex of child on enrolment levels is therefore likely to be negligible. Another demographic variable, age, was also examined, and in Table 1, the descriptive analysis shows that the category 6-9 years 
contained a highest percentage (25.8\%) that had never enrolled in school, while the age category 14-17 years had the largest numbers previously enrolled (15.8\%) and finally the age group 10-13 years had its biggest number of those currently enrolled (91.8\%).Table 2 and Figure 1 report results for the entropy scores and the entropy index, which ideally measures the degree of evenness with regard to enrolment among the various groups of the study population. The entropy scores that measure the diversity in the enrolment status show that there is indeed some degree of diversity in the enrolment status in the various regions of the country, for example the entropy index of 0.308 associated with region of residence is an indicator of the extent to which enrolment levels in the regions are unevenly distributed. Likewise it can be seen from Table 2 that for all variables the estimated entropy values were larger than zero, indicating that enrolment levels among children in Uganda is a fairly diversified.

Table 2: Entropy scores $\left(E_{i}\right.$ 's) and Theil Index (H) by selected study population groups

\begin{tabular}{|c|c|c|c|}
\hline $\begin{array}{l}\text { Variable/ } \\
\text { Category }\end{array}$ & Number (n) & $\begin{array}{l}\text { Entropy Score } \\
\text { for sub-group }\left(E_{i}\right)\end{array}$ & $\begin{array}{l}\text { Entropy } \\
\text { Index (H) } \\
\end{array}$ \\
\hline \multicolumn{4}{|l|}{ Region } \\
\hline Central & 2,754 & 0.551 & \\
\hline Eastern & 2,984 & 0.453 & 0.308 \\
\hline Northern & 4,055 & 0.698 & \\
\hline Western & 2,631 & 0.579 & \\
\hline \multicolumn{4}{|l|}{ Residence } \\
\hline Rural & 10,986 & 0.602 & 0.418 \\
\hline Urban & 1,438 & 0.507 & \\
\hline \multicolumn{4}{|l|}{ Poverty Indicator } \\
\hline Non-poor & 8,456 & 0.516 & 0.537 \\
\hline Poor & 3,968 & 0.717 & \\
\hline \multicolumn{4}{|l|}{ Household size } \\
\hline $1-3$ & 782 & 0.691 & \\
\hline $4-6$ & 4,619 & 0.616 & 0.133 \\
\hline $7-9$ & 4,998 & 0.589 & \\
\hline $10+$ & 2,025 & 0.491 & \\
\hline \multicolumn{4}{|l|}{ Sex of child } \\
\hline Male & 6,321 & 0.589 & 0.310 \\
\hline Female & 6,103 & 0.598 & \\
\hline \multicolumn{4}{|l|}{ Age Group } \\
\hline 6-9 years & 4,770 & 0.610 & \\
\hline 10-13years & 4,271 & 0.329 & 0.173 \\
\hline 14-17 years & 3,383 & 0.613 & \\
\hline Overall score (E) & - & 0.593 & - \\
\hline
\end{tabular}

Table 3 shows the log odds of a child being enrolled and also having previously enrolled as opposed to never enrolling in school. The findings suggest that the relative $\log$ odds of a child being enrolled as opposed to never enrolling in school were higher in Eastern region of
Uganda compared to Central region $(\mathrm{OR}=1.549, \mathrm{p}=0.000)$. On the other hand there was a reduction in the likelihood of a child enrolling in school if the child hailed from Northern region compared to Central region $(\mathrm{OR}=0.595 ; \mathrm{p}=0.000)$. The latter finding could be a reflection of the post civil war situation in this region of the Uganda, characterized by unattractive school environments and often traumatized children soldiers (Women's Commission for Refugee Women and Children, 2005). The low enrolment rates in Northern Uganda could also be attributed to the high poverty levels which have slowed down progress in service delivery including education [23] Results presented in Table 3 also show that the log odds of a child being previously enrolled in school as opposed to never enrolling in school were not significantly different in Central and Eastern regions. However, previous enrolment reduced significantly as opposed to never enrolled for Northern and Western regions, respectively.

Table 3: Multinomial logistic regression predicting the odds of a child school enrolment outcomes (base category= never enrolled)

\begin{tabular}{|c|c|c|c|c|}
\hline \multirow{2}{*}{$\begin{array}{l}\text { Variable/ } \\
\text { Category }\end{array}$} & \multicolumn{2}{|c|}{ (Currently Enrolled) } & \multicolumn{2}{|c|}{ (Previously enrolled) } \\
\hline & RRR & Significance & RRR & Significance \\
\hline \multicolumn{5}{|l|}{ Region } \\
\hline Central $^{\mathrm{RC}}$ & 1.000 & - & 1.000 & - \\
\hline Eastern & 1.549 & 0.000 & 1.015 & 0.927 \\
\hline Northern & 0.595 & 0.000 & 0.487 & 0.000 \\
\hline Western & 0.833 & 0.063 & 0.639 & 0.005 \\
\hline \multicolumn{5}{|l|}{ Residence } \\
\hline Rural $^{\mathrm{RC}}$ & 1.000 & - & 1.000 & - \\
\hline Urban & 1.645 & 0.000 & 1.541 & 0.013 \\
\hline \multicolumn{5}{|l|}{ Poverty Indicator } \\
\hline Non-poor ${ }^{\mathrm{RC}}$ & 1.000 & - & 1.000 & - \\
\hline Poor & 0.417 & 0.000 & 0.638 & 0.000 \\
\hline \multicolumn{5}{|l|}{ Household size } \\
\hline $1-3^{R C}$ & 1.000 & - & 1.000 & - \\
\hline $4-6$ & 1.269 & 0.081 & 0.803 & 0.246 \\
\hline $7-9$ & 1.330 & 0.037 & 0.702 & 0.063 \\
\hline $10+$ & 1.611 & 0.002 & 0.652 & 0.053 \\
\hline \multicolumn{5}{|l|}{ Sex of child } \\
\hline Male $^{\mathrm{RC}}$ & 1.000 & - & 1.000 & - \\
\hline Female & 0.927 & 0.199 & 0.987 & 0.898 \\
\hline Age (continuous) & 5.415 & 0.000 & 3.613 & 0.000 \\
\hline Age squared & 0.936 & 0.000 & 0.969 & 0.000 \\
\hline
\end{tabular}

The relative $\log$ odds of being currently enrolled as opposed to never enrolled in school were significantly higher in urban areas compared to rural areas $(\mathrm{OR}=1.645$, $\mathrm{p}=0.000$ ). This latter finding was expected given the fact that in urban areas there are more schooling facilities and opportunities compared to the rural areas. Results for the 
second outcome - previous enrolment, suggest that the urban areas also exhibit higher log odds of previous enrolment compared to rural areas. This latter finding is consistent with previous studies which indicate that the chances of children from urban areas dropping out of school are usually higher compared to rural areas [38].

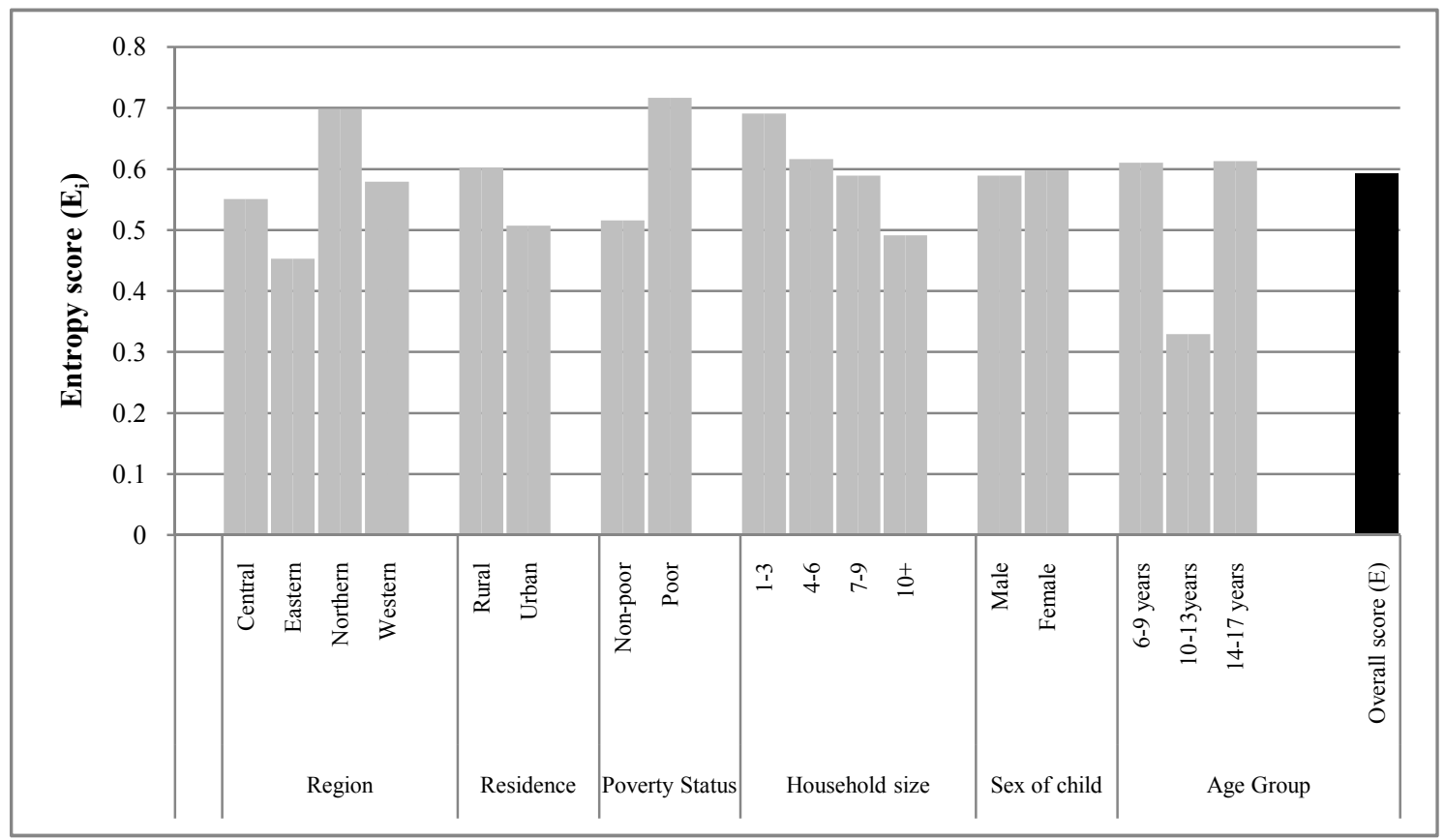

Figure 1: Entropy Scores (E) for study population sub-groups

The results in Table 3 further show that the relative odds of currently enrolling as opposed to never enrolling in school reduced if the child resided in a poor household $(\mathrm{OR}=0.417 ; \mathrm{p}=0.000)$ compared to a non-poor household. The findings also show that the poor were more likely to have been previously in school compared to the non-poor. In a related study, Rutaremwa (2013), showed that children from poor households were more likely to be education deprived. As earlier noted, poverty slows down investment in service delivery and school enrolment is usually affected and is also likely to increase the rate of dropout from schools [22]. Household size was another significant variable in the model. The findings show that larger household sizes, were associated with an increase in enrolment compared to smaller households. This finding is consistent with the view held by some researchers who posit that there are positive educational effects of larger families [33, 34, 35].

A one-year increase in the variable age was associated with a 5.4 increase in the relative log odds of being in currently enrolled category as opposed to the never enrolled category. This latter pattern of results was also observed in the never enrolled category, where a unit increase in age was associated with a 3.6 increase in the log-odds of being previously enrolled category as opposed to the never enrolled category. The significant coefficients for the squared terms of the variable age are suggestive of the fact that the relationship between age and current enrolment as well as previous enrolment is quadratic. The latter finding also suggests that the nature of relationship between age and current enrolment as well as previous enrolment gets less positive as the child gets older.

One of the findings of this study was that there were no significant gender differences in access to education in the age group $6-17$ year. The latter finding is consistent with previous research[3], which revealed that in Uganda the gender gap in access to education was diminishing. The importance of a more detailed gender analysis is recommended to generate findings that would inform gender specific interventions both in Uganda and elsewhere.

\section{Conclusion}

The relevance of a country achieving equality in access to education cannot be overemphasized here. In this paper data from the UNHS survey of 2009/2010 have been analyzed to illustrate how inequalities in access to education still exist in Uganda, two decades after the introduction of the UPE programme. The findings in this paper have important implications for interventions to address education inequalities among children aged 6-17 years. The results also reveal that regional inequalities in access to education are still significantly persistent in the country. The latter finding suggests that any interventions to reduce inequality in access to education must by design target those regions of the country that are facing education deprivation, especially Northern and Western regions. Similarly, rural areas of the country must be targeted for educational interventions to bring equality in access to this basic need for children. Whereas the policies of UPE have reported some success for primary enrolments in Uganda, which is good news, it is also important to note that 
segments of children population especially those from poor households continue to be education deprived. The important policy challenge is to give particular attention to these children who are education deprives a commitment to improving their access to this basic need.

\section{References}

[1] P. Brunori, V. Peragine, and L. Serlenga, "Fairness in education: The Italian university before and after the reform," Economics of Education Review, vol. 31, no. 5, pp. 764-777, Oct. 2012.

[2] F. W. Juuko and C. Kabonesa, "Universal Primary Education in Uganda (UPE) in Contemporary Uganda: Right or Privilege? HURIPEC Working Paper Number 8.," no. 8. Kampala, Uganda, 2007.

[3] R. Wells, "Gender and age-appropriate enrolment in Uganda," International Journal of Educational Research, vol. 48, no. 1, pp. 40-50, Jan. 2009.

[4] World Bank, "World Development Report 2006: Equity and Development," Washington, DC., 2005.

[5] F. Bourguignon, “'Distribution, Equity and Development.',' in in Equity and Development, G. K.-L. and B. Pleskovic, Ed. Washington, DC.: World Bank., 2006, pp. 39-45.

[6] F. Bourguignon and S. Dessus, “"Equity andDevelopment: Political Economy Considerations.'," in in No Growth withoutEquity? Inequality, Interests and Competition in Mexico, S. Levy and M. Walton, Eds. Washington, DC.: World Bank, 2007, pp. 45-70.

[7] P. Aghion and P. Bolton, "A theory of trickle-down growth and development.," Review of Economic Studies, vol. 64, no. 2, pp. 151-172, 1992.

[8] A. Banerjee and A. Newman, "Occupational choice and the process of development.," Journal of Political Economy, vol. 101, no. 2, pp. 274-298, 1993.

[9] O. Galor and J. Zeira, "Income distribution and macroeconomics.," Review of Economic Studies, vol. 60, no. 1, pp. 35-52, 1993.

[10] T. Piketty, "Theories of persistent inequality and intergenerational mobility," in in Handbook of income distribution, A. B. Atkinson and F. Bourguignon, Eds. Amsterdam: Elsevier, 2000, pp. 429-476.

[11] E. Hanushek and L. Wößmann, "Education Quality and Economic Growth.,"Washington, DC., 2007.

[12] M. Ravallion, "'Should Poor People Care about Inequality?," in in Equity and Development, G. Kochendörfer-Lucius and B. Pleskovic, Eds. Washington, DC.: World Bank., 2006, pp. 89-101.

[13] P. Stevens and M. Weale, "'Education and Economic Growth.'," in in International Handbook on the Economics of Education, G. Johnes and J. Johnes, Eds. Camberley: Edward Elgar, 2004, pp. 164-188.

[14] L. Song, S. Appleton, and J. Knight, "Why do girls in rural China have lower school enrollment?," World Development, vol. 34, no. 9, pp. 1639-1653, 2006.
[15] C. Buchmann, T. A. DiPrete, and A. McDaniel, "Gender inequalities in education," Annu. Rev. Sociol, vol. 34, pp. 319-337, 2008.

[16] C. M. Mabika and D. Shapiro, "School Enrollment in the Democratic Republic of the Congo: Family Economic WellBeing, Gender, and Place of Residence," 2011.

[17] K. Higgins, "Regional inequality and primary education in Northern Uganda - Resources - Overseas Development Institute (ODI).” 2007.

[18] World Bank, "Poverty and Vulnerability Study," Washington DC, 2006.

[19] S. Klasen, "Gender and growth in Uganda: Some preliminary findings and policy issues," New York, 2004.

[20] S. Klasen, "Low Schooling for Girls, Slower Growth for All? Cross-Country Evidence on the Effect of Gender Inequality in Education on Economic Development," The World Bank Economic Review, vol. 16, no. 3, pp. 345-373, 2002.

[21] V. J. Roscigno, D. Tomaskovic-Devey, and M. Crowley, "Education and the Inequalities of Place," Social Forces, vol. 84, no. 4, 2006.

[22] World Bank, "Republic of Uganda Joint IDA-IMF Staff Advisory Note on the Poverty Reduction Strategy paper Annual Progress Report," 2007.

[23] K. Deininger, "Does cost of schooling affect enrollment by the poor? Universal primary education in Uganda," Economics of Education Review, vol. 22, no. 3, pp. 291-305, Jun. 2003.

[24] G. Rutaremwa, "Child Poverty in Uganda: Analysis of the UNHS 2009/2010 Survey," American Journal of Sociological Research, vol. 3, no. 2, pp. 36-45, 2013.

[25] M. Montgomery, A. Kouame, and R. Oliver, "The Tradeoff Between Number of Children and Child Schooling: Evidence from Cote D'Ivoire and Ghana (Living Standards Measurement Study Working Paper No. 112).” New York, 1995.

[26] M. Schafer, "Family school enrolment in rural Malawi and Kenya: A regional analysis," Comparative Sociology, vol. 3, no. 1, pp. 37-68, 2004.

[27] D. Shapiro, R. Marcoux, M. Pilon, and A. Quesnel, "Family influences on women's educational attainment in Kinshasa," in in Education, family and population dynamics, M. Cosio, R. Marcoux, M. Pilon, and A. Quesnel, Eds. Paris: Committee for International Cooperation in National Research in Demography (CICRED)., 2003.

[28] M. Tembon and S. Al-Samarrai, "Who gets primary schooling and why? Evidence of gender inequalities within families in Guinea." Sussex, 1999.

[29] M. Gomes, "Family size and educational attainment in Kenya," Population and Development Review, vol. 10, pp. 647-660, 1984.

[30] P. M. Eloundou-Enyengue and J. Davanzo, "Economic downturns and schooling inequality, Cameroon, 1987-95," Population Studies, vol. 57, no. 2, pp. 183-197, 2003.

[31] UHRC, "Uganda Human Rights Commission 7th Annual Report 2004,” Kampala, Uganda, 2004. 
[32] G. Arcia, H. A. Patrinos, E. Porta, and K. Macdonald, “'School Autonomy and Accountability: System Assessment for Benchmarking Education for Results, Regulatory and Institutional Framework.'," Washington, DC., 2011.

[33] Republic of Uganda Ministry of Education \& Sports, "Education and Sports Sector Fact Sheet 2000 - 2012," 2012. [Online]. Available: http://www.education.go.ug/files/downloads/Fact 2012 final.pdf. [Accessed: 28-May-2013].

[34] A. Wandira, Early missionary education in Uganda: A study of purpose in missionary education. Kampala: Makerere University Printery, 1972.

[35] J. N. Aguti, "Facing up to the Challenge of Universal Primary Education, ( UPE) in Uganda through Distance
Teacher Education Programmes," in $P A N$ COMMONWEALTH FORUM ON OPEN LEARNING: Open Learning: Transforming Education for Development, 2002, no. August.

[36] Republic of Uganda Ministry of Education \& Sports, "The Ugandan Experience of Universal Primary Education (UPE)," 1999.

[37] Republic of Uganda Ministry of Education \& Sports, "Government White paper on The Education Policy Review Commission Report on Education for National Integration and Development," Kampala, Uganda, 1992.

[38] V. J. Roscigno, D. Tomaskovic-Devey, and M. Crowley, "Education and the inequalities of place," Social Forces, vol. 84, no. 4, pp. 2121-2145, 2006. 